\title{
Communication strategies and persuasion as core components of shared decision-making for children with life-limiting conditions: a multiple case study
}

\author{
Authors and Affiliations \\ Emma Popejoy ${ }^{1}$ \\ Kathryn Almack ${ }^{3}$ \\ Joseph C. Manning ${ }^{1,4}$ \\ Bridget Johnston ${ }^{2}$ \\ Kristian Pollock ${ }^{4}$ \\ ${ }^{1}$ Nottingham Children's Hospital, Nottingham University Hospitals NHS Trust, Nottingham, UK. \\ ${ }^{2}$ University of Glasgow, School of Medicine, Dentistry and Nursing Glasgow, UK and \\ NHS Greater Glasgow and Clyde, Scotland, UK \\ ${ }^{3}$ University of Hertfordshire, School of Health and Social Work, Hertfordshire, UK \\ ${ }^{4}$ University of Nottingham, School of Health Sciences, Nottingham, UK
}

\section{Correspondence}

Dr Emma Popejoy

Ward D33, Queens Medical Centre, Nottingham University Hospitals NHS Trust, Derby Road, Nottingham, NG7 2UH

Emma.popejoy@nuh.nhs.uk 


\section{ABSTRACT}

\section{Background}

Families and professionals caring for children with life-limiting conditions face difficult healthcare decisions. Shared decision-making is promoted in many countries, however little is known about factors influencing these processes.

\section{Aim}

To explore the communication strategies used in shared decision-making for children with life-limiting conditions.

\section{Design}

A longitudinal, qualitative, multiple-case study. Cases were centred around the child and parent/carer(s). Most cases also included professionals or extended family members. Data from interviews, observations and medical notes were re-storied for each case into a narrative case summary. These were subject to comparative thematic analysis using NVivo11.

\section{Setting/participants}

Eleven cases recruited from three tertiary hospitals in England. 23 participants were interviewed (46 interviews). Cases were followed for up to 12 months between December 2015 and January 2017. 72 observations were conducted and the medical notes of 9 children reviewed.

\section{Findings}

Strategies present during shared decision-making were underpinned by moral work. Professionals presented options they believed were in the child's best interests, emphasising their preference. Options were often presented in advance of being necessary to prevent harm, therefore professionals permitted delay to treatment. Persuasion was utilised over time when professionals felt the treatment was becoming more urgent and when families felt it would not promote the child's psychosocial wellbeing.

\section{Conclusions}

Communication strategies in shared decision-making are underpinned by moral work. Professionals should be aware of the models of shared decision-making which include such communication strategies. Open discussions regarding individuals' moral reasoning may assist the process of shared decision-making.

\section{What is already known about this topic?}

- Complex decisions may be required for children with life-limiting conditions, including artificial nutrition, commencement or discontinuation of medications, long term ventilation, and ceilings of care.

- A variety of factors impact on decision making for this population, including factors specific to the family, the decision under consideration and the relationships between families and health care professionals within which the decisions are made.

- Shared decision-making is promoted within paediatric palliative care, yet numerous barriers to its implementation exist. 


\section{What this paper adds.}

- The study highlights that treatments are presented well in advance of when they are considered essential by professionals and that they are communicated with a strong emphasis on the professional's preferred option

- Proposed treatments are often rejected by families initially and over an extended period of time; persuasion is used within the process of shared decision-making.

- Individuals' moral assessments of the child's best interests underpin their use of these strategies.

\section{Implications for practice.}

- Professionals should be aware of the models of shared decision-making which promote persuasion as core attributes.

- Professionals should enable discussion of each individuals' moral reasoning, including their own, regarding decision making to better understand any disagreements and facilitate shared decision-making.

Keywords: Child; Child, preschool; Adolescent; Decision-making; Qualitative research; Palliative care; Longitudinal studies; Family 


\section{Introduction}

Children with life-limiting and life-threatening conditions have fluctuating disease stages, transitioning frequently between stable, unstable and deteriorating, prior to the dying stage ${ }^{1}$. Periods of instability provoke difficult decisions, including tube-feeding, medication decisions, and withholding or withdrawing life-sustaining treatment ${ }^{2}$.

The availability of multiple options presents moral dilemmas and the requirement for moral reasoning in medical decision-making ${ }^{3}$. The necessity of parents' moral work in relation to their child's medical care, defined as "attend[ing] to the issue of their appearance as moral persons, competent members and adequate performers...in formulating their accounts, they accomplish the status of moral adequacy" ${ }^{\prime \prime}$, P276, has been recognised. Moral work is particularly necessary in uncertain decisions, where an individual's moral adequacy may be questioned ${ }^{5}$.

For decisions involving uncertainty, shared decision-making is promoted as the gold-standard in many countries $^{6}$. Yet the definition of shared decision-making, particularly within paediatrics, has been elusive. A recent concept analysis defined paediatric shared decision-making as "active participation of parents, children and health professionals in reaching a compromise via collaborative partnership, with a common goal for child's health"7, P.482. Research has identified that decision factors, relational factors, perceived capability and willingness for engagement and time available for discussion, influence the implementation of shared decision-making within paediatrics ${ }^{8}$. Furthermore, disagreements can result from different moral perspectives regarding the child's best interests ${ }^{9}$ and consideration of the wider family's best interests ${ }^{10}$. The power imbalance in the patient-professional relationship adds further complexity ${ }^{11}$, as do the legal limits regarding proxy decision-makers ${ }^{12}$. The courts become the ultimate arbitrator of the child's best interests during unresolvable disagreements ${ }^{10,13,14}$.

Shared decision-making has been viewed as requiring provision of value-neutral facts ${ }^{15}$. More recently bioethics literature has recognised persuasion, "a successful intentional effort at influencing another's mental state through communication in a circumstance in which the persuade has some measure of freedom $^{116, p .4}$, as an important part of shared decision-making. Persuasion can promote patient involvement by encouraging consideration of the options ${ }^{17}$ and increase autonomy, by raising awareness of any unconscious biases working against patients' overall values ${ }^{18}$. Despite this growing recognition, such strategies are absent from the concept analysis of shared decision-making in paediatrics ${ }^{7}$.

\section{Aim}

This was part of a broader study exploring decision-making for children with life-limiting conditions. This article examines one aspect of the findings; the strategies used in shared decision-making.

\section{Methods}

\section{Study design}

This multiple case study ${ }^{19}$ was underpinned by social constructionism which aims to understand peoples' interpretation of their experiences, recognising that individuals interpret their experiences differently ${ }^{20}$ and that multiple conflicting interpretations of the same event exist ${ }^{21}$. These various interpretations were re-storied into case narratives, which facilitated a cross-case analysis. The study 
utilised a generic qualitative approach, one which is "not guided by an explicit or established set of philosophic assumptions in the form of one of the known qualitative methodologies" 22. This approach enables focussed attention on the research question, rather than modifying it to fit a particular methodology ${ }^{23}$.

The study was conducted between December 2015 and January 2017. Data collection had to be completed by January 2017 (to ensure that this doctoral study was completed within the time allowed by the University), therefore the exact period of participation was dependent on recruitment date (with a maximum of 12 months). The consolidated criteria for reporting qualitative studies (COREQ) have been followed in reporting.

\section{Setting}

Participants were recruited from three tertiary hospitals in England.

\section{Participants}

Each case was centred around a child with a life-limiting condition in categories 2-4 (defined by ACT and $\mathrm{RCPCH}{ }^{24}$, Error! Reference source not found.) and their family.

Category 1 - Conditions for which curative treatment may be feasible but can fail

Category 2 - Conditions where premature death is inevitable

Category 3 - Progressive conditions without curative treatment options

Category 4 - Irreversible but non-progressive conditions causing severe disability, leading to susceptibility to health.

Box 1: Categories of life-limiting and life-threatening conditions

Families were invited to nominate 'significant others' (lay or professional individuals) who they considered important in their decision-making to also participate in interviews, as part of their case. The actual boundary of each case was much broader than this, given the vast number of professionals and individuals providing social support present at observations (Figure 1).

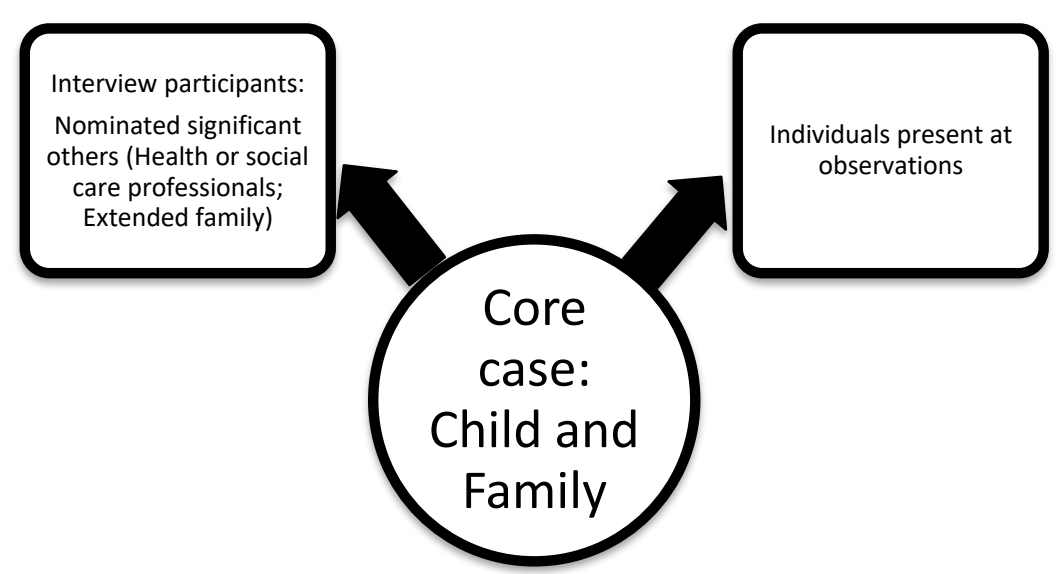


The minimum requirements for a case to be included were that there was at least one interview with the child and/or parent/carer(s) or more than one observation. Figure 2 displays eligibility criteria for the interview participants.

\section{Inclusion criteria - Parent}

- Their child must be between 28 days and 18 years old

- Their child must have a life-limiting condition within categories 2-4 (Box 1)

- Their child must be under the care of a consultant at either of the three NHS Trusts included in the study

- The parent must be aware of the child's diagnosis

-Participants must speak English. This is both due to resource constraints and due to the complex and sensitive topic which means that the use of interpreters would not be feasible or appropriate.

\section{Inclusion criteria - Child}

- Must be between 28 days and 18 years old

-Must have a life-limiting condition within categories 2-4 (Box 1

- Must be under the care of a consultant at either of the three NHS Trusts included

in the study

- Child interview participants must be over the age of 7 years and cognitively able to provide their own assent (or consent, if over 16 years old)

- Parents must have provided consent for the child's participation if they are under 16 years old

-Interview participants must speak English or be able to communicate in some way using alternative or augmentative communication.

\section{Inclusion criteria - Significant Others / Professionals}

- Significant others must have been identified by the eligible child and/or parents as being important in their decision making and future planning

-Participants must speak English

- Participants must be over the age of 7 years and provide their own assent alongside parental consent (if under 16 years old) or provide consent if they are over the age of 16 years (in the case of a friend or sibling being nominated as a 'significant other').

\section{Inclusion criteria - Peripheral participants}

-Any individual present at observations who has input into decisions.

\section{Exclusion criteria}

-Families and significant others of children with Category 1 (Box 1) life-limiting conditions.

-Participants who do not meet the inclusion criteria.

Figure 2: Eligibility Criteria

\section{Sampling}

Purposive sampling was used to recruit cases (children with life-limiting conditions and their parent/carer(s)) with experience of decision-making, from three hospitals. Significant others were recruited through snowball sampling, where families nominated individuals who assisted them in decision-making; this was theoretically driven by the research question, rather than representativeness ${ }^{25}$. 


\section{Recruitment}

Clinical teams identified eligible families, to form the core of each case, and sent them an invitation letter and Participant Information Sheets. Interested families returned a reply slip, consenting to contact from the researcher.

Written informed consent was obtained from parent/carer(s) and where possible assent was obtained from children. Nominated significant others were contacted by EP and sent study information via post or email.

Professionals anticipated to be present at observations were emailed study information in advance and provided written consent to be observed. When this was not possible, they were informed about the research immediately prior to the observation and provided verbal consent, which was deemed proportional to their participation ${ }^{26}$.

\section{Data collection}

The study utilised semi-structured interviews, observations, and medical notes review. It included the perspectives of children, parents, extended family, and professionals. All appointments or meetings during which the child's care would be discussed were observed, where possible, including outpatient appointments, inpatient ward rounds and Team Around the Child meetings. Recruited families provided details of scheduled appointments.

The number and frequency of observations varied from case to case, depending on the complexity of the child's clinical condition. An initial interview was undertaken with each interview participant and a final interview served as the endpoint for each case. In some cases a third interview was conducted part-way through the data collection period. A topic guide (Supplemental File 1) aided initial interviews and included the individuals' knowledge of the child and their condition, previous decisions and outcomes, anticipated decisions and individuals involved in decision-making. Subsequent interviews were guided by previous data collection. Regular contact with families identified additional upcoming appointments.

Interviews were audio-recorded and observations documented using field-notes. Following completion of all interviews and observations, the children's medical records were accessed and information relevant to decision making (for example, clinic letters or medical documentation detailing considerations or discussions regarding treatment decisions) was anonymised and copied.

\section{Data analysis}

EP transcribed audio data verbatim. Detailed notes were made from field notes immediately after observations. Narrative case summaries were compiled for each case in order to "make the case comprehensible"27, P.124. These were compiled from interview, observation and medical notes data, using the three-dimensional approach (social, temporal and situational) discussed by Clandinin and Connelly ${ }^{28}$. Case summaries maintained the temporal nature of the data and the multiple perspectives of informants, in a process of re-storying ${ }^{29}$. Thematic analysis of case summaries in NVivo11 facilitated exploration of commonalities and differences across $\operatorname{cases}^{30}$ (Figure 3 ).

Discussion between authors enabled themes to be interrogated and modified, enhancing transparency and rigour. Reflexivity and attention to the specific contexts of data collection ensured research credibility ${ }^{25}$. 


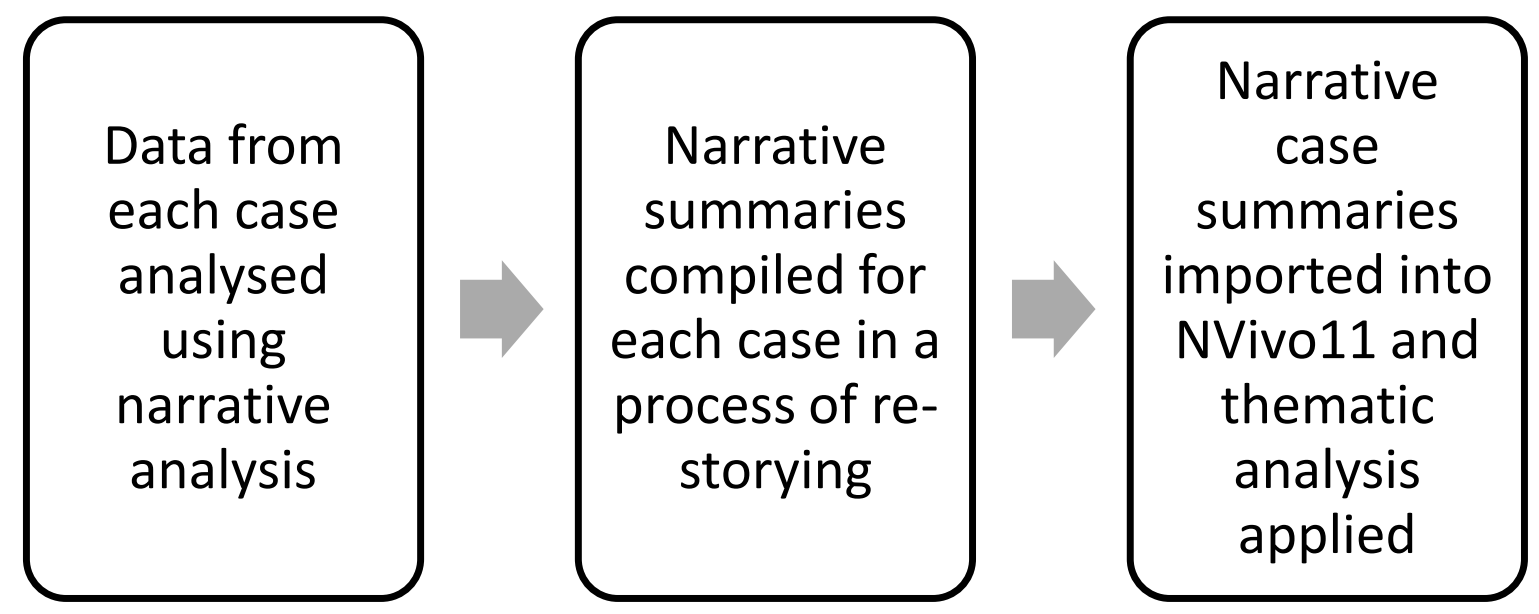

Figure 3: Process of analysis

\section{Ethical considerations}

NHS Research Ethics Committee (Nottingham 1 REC - 15/EM/0377) and governance approvals were obtained. Detailed attention was given at each point of contact to participants' willingness to participate, in an ongoing process of consent ${ }^{31}$. The multiple informants within a case required detailed attention to confidentiality, ensuring that information was not shared between participants. Child participants were informed of the researcher's duty of care and requirement to share information if they disclosed anything suggesting the risk of harm.

\section{Findings}

Eleven cases were recruited (Table 1). One family withdrew after one month and in one case, the family elected to only take part in one interview. Table 1 outlines the data collected per case.

This article focuses on the strategies used and positions these within the context of shared decisionmaking. It will discuss the (1) communication of choice and options, (2) persuasion, and (3) how moral work underpins these strategies. Tube-feeding was the most frequently identified contentious decision. The children in nine of the cases were tube-fed and in six cases, this decision resulted in disagreement. A cross-case analysis of disagreement relating to tube-feeding is used to illustrate the findings. 


\begin{tabular}{|c|c|c|c|c|c|c|}
\hline Case & $\begin{array}{l}\text { Child's } \\
\text { Pseudonym }\end{array}$ & $\begin{array}{l}\text { Child's } \\
\text { Characteristics }\end{array}$ & $\begin{array}{l}\text { Interview participants } \\
\text { Pseudonyms (Role, number of } \\
\text { interviews) }\end{array}$ & $\begin{array}{l}\text { Total number } \\
\text { of interviews }\end{array}$ & $\begin{array}{l}\text { Number of } \\
\text { Observations }\end{array}$ & $\begin{array}{l}\text { Notes } \\
\text { Review }\end{array}$ \\
\hline 1 & Daisy & $\begin{array}{l}\text { 2yr Female, Category } \\
2^{¥}\end{array}$ & $\begin{array}{l}\text { Catherine \& Steve (Mum \& Dad, } \\
\text { 1) } \\
\text { Catherine (Mum, 2) }\end{array}$ & 3 & 5 & $\checkmark$ \\
\hline 2 & Maisie & $\begin{array}{l}\text { 1yr Female, Category } \\
3^{¥}\end{array}$ & $\begin{array}{l}\text { Fiona (Mum, 3) } \\
\text { Dr Price (Paediatrician, 2) } \\
\text { Dr Chase (Cardiologist, 2) } \\
\end{array}$ & 7 & 12 & $\checkmark$ \\
\hline 3 & Grace & $\begin{array}{l}\text { 10yr Female, Category } \\
4^{¥}\end{array}$ & $\begin{array}{l}\text { Kay (Mum, 3) } \\
\text { Dr Price (Paediatrician, 2) } \\
\text { Alice (School nurse, 2) }\end{array}$ & 7 & 4 & $\checkmark$ \\
\hline 4 & Michael & 10yr Male, Category $3^{¥}$ & $\begin{array}{l}\text { Kate (Mum, 3) } \\
\text { Michael (3) } \\
\text { Gail (Family Support Worker, 1) }\end{array}$ & 7 & 5 & $\checkmark$ \\
\hline 5 & Elena & $\begin{array}{l}\text { 10yr Female, Category } \\
3^{\ddagger}\end{array}$ & $\begin{array}{l}\text { Pauline (Mum, 3) } \\
\text { Joanna (Physiotherapist, 1) }\end{array}$ & 4 & 7 & $\checkmark$ \\
\hline 6 & Omar & 4yr Male, Category $4^{¥}$ & $\begin{array}{l}\text { Nadia (Mum, 3) } \\
\text { Hafisa (Omar's Cousin, 1) }\end{array}$ & 4 & 9 & $\checkmark$ \\
\hline 7 & Hassan & 1yr Male, Category $4^{*}$ & Salma (Mum, 2) & 2 & 11 & $\checkmark$ \\
\hline 8 & Christopher & $12 y r$ Male, Category $4^{¥}$ & $\begin{array}{l}\text { Susan (Mum, 3) } \\
\text { Dr Brett (Paediatrician, 2) }\end{array}$ & 5 & 8 & $\checkmark$ \\
\hline 9 & Charlotte & $\begin{array}{l}\text { 14yr Female, Category } \\
2^{¥}\end{array}$ & $\begin{array}{l}\text { Charlotte and Rachel (Mum, 3) } \\
\text { Jamie (Dad, 2) } \\
\text { Jessica (Specialist Nurse, 1) }\end{array}$ & 6 & 8 & $\checkmark$ \\
\hline 10 & Ella & $\begin{array}{l}13 y r \text { Female, Category } \\
4^{*}\end{array}$ & $\mathrm{~N} / \mathrm{A}^{*}$ & 0 & 3 & $\mathrm{~N} / \mathrm{A}^{*}$ \\
\hline 11 & Evie & $\begin{array}{l}\text { 4yr Female, Category } \\
4^{*}\end{array}$ & Anthony \& Ruth (Dad \& Mum, 1) & 1 & N/A** & $\mathrm{N} / \mathrm{A}^{* *}$ \\
\hline
\end{tabular}

*Ella's family withdrew after 3 observations, before an initial interview could be arranged and before the medical notes would have been accessed. **Evie's family felt that that they already had a myriad of professionals involved and did not wish to add another person into their life, and expressed that they felt that it would not be useful for me to follow them for observations. Her parents were keen to, and consented to, participate in one interview. ${ }^{\sharp}$ Categories refer to ACT \& RCPCH Categories of life-limiting and life-threatening conditions (Error! Reference source not found. $)^{24}$ :

Table 1: Case characteristics and participants 


\section{Communication of choice and options}

For many decisions, treatments were initially presented by professionals as possibilities for the future, providing some choice for families regarding the treatment and its timing. These discussions signalled the professional's preferred option, emphasising how it was in the child's best interests. However, professionals tended to present the treatment early, before they believed it was a clinical priority and were happy to acquiesce to families' desire to refuse or delay:

I would have preferred Grace to have had a gastrostomy when she was two...and my feeling was that it was better for her to have a gastrostomy than not but it wasn't dangerous for her not to have one...I was prepared to compromise and whilst care was good enough...I was a bit worried that maybe some of the chesty episodes were related to feeding but that wasn't definitely so and I didn't feel I had enough grounds to push my case against Mum's strong, strong conviction...So, you compromise until you can't compromise anymore because you've got to a position where clearly the child is being put at risk [Dr Price, Grace's Paediatrician].

Professionals were aware of the unique issues surrounding tube-feeding and their impact on families' ability to make this decision.

I think feeding is an interesting one because gastrostomies in particular, parents want to feed, it's the one thing they can do often, or they think they can and so they spend a lot of time trying to safely feed their babies and when you offer them a gastrostomy they don't want it, but then when you put it in, you know their lives are transformed and it's really difficult because we know that that's likely to be transformative, but for them it's taking away something that they do as parents and that's really difficult, so you know there is quite a lot of negotiation and I think convincing in that situation. (Dr Brett, Christopher's Paediatrician)

These challenges appeared to be partially responsible for early initiation of discussions around tubefeeding, temporarily accepting the family's decision against it and ensuring ongoing conversations aimed at persuasion.

\section{Persuasion}

Persuasion incorporated a range of strategies which, during periods of relative stability, involved simple repetition of information over an extended time period:

Every meeting...Dr Price would pressure me, Alice (School Nurse) would pressure me, the SALT team would pressure me, they would come to my house and they bring the doll and they show me the right throat and the wrong throat. [Kay, Grace's Mother]

Often this continual repetition was perceived as pressure, yet families did not concede. Families similarly used this type of persuasion, repeating their own personal heuristics during persuasive endeavours, predominantly appealing to the child's wishes, psychosocial wellbeing and normalisation:

So the hospital were pushing requirement for... and their recommendation for a feeding tube for quite a long time. We knew that that, we felt highly uncomfortable with it for a whole bunch of reasons: we know Charlotte, we know how she would react. We'd been trying to get her to eat and motivate her around eating. We were highly reluctant to 
concede to her having a feeding tube and you know we pushed back really hard on that for quite a long time. [Jamie, Charlotte's Father]

In contrast to families, professionals prioritised the child's physical health during their persuasive endeavours:

You have been trying very hard to keep up Michael's nutrition without him having a tube feed, however...he has not made any significant weight gain in the past 9 months... and is now below the $0.4^{\text {th }}$ centile in both height and weight. I am concerned that this malnutrition will impact on Michael's health in the long run. I know that Michael doesn't want to consider having a gastrostomy, but it is in my view in his best interests to have one now. (Clinic letter from Dr Price to Michael's Mother).

Dr Price's explicit reference to Michael's best interests signalled her increasing concern regarding Michael's health and the reasons behind her persuasive endeavours.

One case identified persuasion in relation to tube-feeding from the family to professionals. Hassan was being gastrostomy fed but was continually vomiting and therefore not thriving. His mother positioned herself as the persuader for jejunostomy placement and fundoplication:

I was like "come on, he keeps vomiting, what is holding you back?" "Well there'll be extensive scar tissue from his duodenal atresia". I was like "but he's not thriving, he's not growing, why don't you just give him the Nissens [fundoplication]?" there was a lot "OK let's see, let's see if he vomits, let's change his milks". I said "my son is going through so much, you're going to give him [the surgery]" (Salma, Hassan's Mother)

Reference to the medical notes identified that, as in Salma's account, the doctors preferred a 'wait and see' approach, but eventually agreed that the surgery would be beneficial.

In all situations, persuasion was based on each individual's knowledge of the child and their assessment of their best interests, signalling to the moral work they were undertaking in decisionmaking.

\section{Increased persuasion and pressure}

During protracted disagreements, persuasion included discussion of the limits to parental decisional responsibility when professionals felt that the child's health was being put at risk. In one case, inference to the limits of parental decisional responsibility was made in advance of this level of concern:

Dr Price did say she'd go on our gut instinct and monitor it, but if she felt it was the time then she would take the appropriate actions, so we did get told she would probably go over our heads. [Pauline, Elena's Mother]

By the end of the study, tube-feeding had been initiated in five of the six cases where it had previously been a source of disagreement. This was a difficult decision for families due to the social implications and desire for normalisation. In three cases explicit or implicit reference to the possibility of escalation to the courts had been made (in one, tube-feeding was still being resisted at the end of the study). Families understood the implicit references to court escalation. Two families found this 
confrontational, but one believed the professional was trying to achieve what they considered was right for their child, signalling some understanding of the moral work undertaken by professionals.

\section{Moral work underpinning these strategies}

Professional perception of the child's best interests influenced how they communicated the options and used persuasion. Professionals described this not in terms of coercion, but rather a duty to support families in arriving at the decision they considered was in the child's best interests. This enabled them to maintain their moral identities, using persuasion to achieve family agreement:

I have a duty to do that and of course I want to. But on the other hand I've got a mummy who isn't seeing what I'm seeing and has a different view. So, what I need to help her to see what I'm seeing and help her to understand why I'm saying what I'm saying. I need to help her to hear what I'm saying and I need to help her to believe what I'm saying and I need her to then agree with me or come on the same, come on my path (Dr Price, Grace's Paediatrician)

Families also described a duty to protect their child's best interests by trying to persuade professionals of their perspective and demonstrate their determination to defend what they believed was best for their child:

I'm not against it, I don't know why people, I'm against it because he's against it...I'm defending something what I know he's so against at the minute and at the end of the day if it comes down to quality of life and him not being so upset, then that's happening. (Kate, Michael's Mother)

The use of these strategies was underpinned by the individual's moral assessment of the child's best interests and their justifications aimed to demonstrate their moral adequacy as decision-makers for the child.

Although it appears that professionals and families were at odds with one another, five out of the six cases which experienced disagreement about tube-feeding, eventually reached a shared-decision to commence tube-feeding by the end of the study.

\section{Discussion}

This study highlights the strategies used in shared decision-making for children with life-limiting conditions. Professionals presented options they believed were in the child's best interests, strongly emphasising their preference and persuasion aimed to resolve disagreements. Each individuals' moral assessment of the child's best interests underpinned their use of these strategies. This analysis helps illuminate how shared decision-making occurs within this complex relational context.

Professionals in this study primarily initiated discussions regarding treatment options. When they deemed one option superior to any other, they communicated the options to portray their preference more positively, or sometimes as the only option. Previous research in the paediatric ${ }^{32-34}$ and neonatal ${ }^{35-37}$ intensive care unit has identified similar communication strategies, influenced by personal factors specific to the professional. Professionals in this study articulated a moral duty to communicate options in a way which facilitated parental agreement when they believed one option was clearly superior. Nevertheless, they allowed decisions that, although not best, were not harmful, alluding to the zone of parental discretion ${ }^{38}$. 
Our data suggest that in many cases there is some degree of equipoise; even when professionals felt the child was at some risk of harm, families' desire to delay the decision was tolerated. Despite allowing families to delay, professionals used persuasion when they felt treatment was in the child's best interests. The bioethics literature suggests a professional obligation to try to persuade patients to accept their advice ${ }^{18,39-41}$; this appeared to be keenly felt by professionals in this study. Persuasion has been identified in studies investigating shared decision-making in paediatric chronic illness ${ }^{42,43}$, yet the underlying moral work has not been identified. Our data demonstrated how individuals' moral viewpoints compelled them to present the options in a certain way or engage in persuasion.

As professionals became more concerned regarding harm, they inferred the possibility of escalation to court, which was underpinned by a moral concern for the child's best interests. Reference to court escalation as a means of persuasion has been identified in end-of-life decisions in paediatric intensive care ${ }^{44}$. However, little evidence exists regarding discussion of court escalation as persuasion in decisions for non-life-sustaining treatments. This threat of court escalation demonstrates the underlying power-imbalance in the family-professional relationship. This power-imbalance enables professionals to communicate choice in a way which biases their preferred option and use persuasion during disagreements.

Our findings suggest that shared decision-making, when described as involving a neutral presentation of the treatment options, does not occur. Nevertheless it was observed that decisions were shared. Previous research suggests that professionals believe they achieve shared decision-making even when using persuasion ${ }^{45,}{ }^{46}$ and that this is acceptable to parents ${ }^{46}$. Our data, in conjunction with this literature, suggests that paediatric shared decision-making occurs via a "professionally driven best interest compromise model" ${ }^{\prime \prime 7}$, P.80, which involves strategic framing of the decision, whilst involving the patient and surrogates in decision-making. A greater awareness of this model within paediatrics would be valuable for clinicians to aid them in their communication with families and in their attempts to share decisions.

Moral pluralism can result in disagreements ${ }^{48}$ in decision-making. Individuals' moral work compelled them to employ persuasion to ensure treatment progressed in accordance with their varying assessments of the child's best interests. Candid communication of moral reasoning can facilitate consensus, or identify the reasons for persisting disagreement, helping identify and resolve tensions ${ }^{48}$. A framework for such discussions within paediatric decision-making ${ }^{10}$ recognises that what is right in each situation can only be understood through discussion of the relationships within which they occur. Undertaking these conversations may also assist in the process of shared decision-making, yet this requires further research.

\section{Strengths and weaknesses of the study}

The longitudinal design, multiple methods used, and perspectives elicited, increase the credibility of this research and facilitated an understanding of the complex context of shared decision-making. The exclusion of non-English speaking families represents a limitation. The maternal voice was dominant; therefore the strategies used in shared decision-making by fathers and children may be underrepresented.

\section{What the study adds}

This study highlighted the strategies utilised within shared decision-making and demonstrated how moral work implicitly guides their use. Professionals should be aware of the models of shared decision- 
making within which strategic action aimed at persuasion, alongside family involvement in decisionmaking, is promoted. Discussing the moral reasoning underpinning individuals' preferences may facilitate bridging between these perspectives and prevent protracted disagreements.

\section{Conclusion}

This study demonstrates how professionals use communication and persuasion to promote their preferred treatment option within shared decision-making for children with life-limiting conditions. This is based on their moral assessment of the child's best interests. Disagreements occurred when differing moral viewpoints existed, resulting in persuasion. Persuasion was a core component of shared decision-making observed in this study, yet is not widely accepted in the literature. Professionals should be assured that persuasion is morally acceptable and commensurate with certain models of shared decision-making. Open discussions regarding the moral reasoning behind individuals' decision-making may better facilitate shared decision-making. However, frameworks to assist with such discussions require further research. 


\section{References}

1. Jarvis S, Parslow RC, Carragher P, Beresford B and Fraser LK. How many children and young people with life-limiting conditions are clinically unstable? A national data linkage study. Archives of Disease in Childhood. 2017; 102: 131-8.

2. Popejoy E, Pollock K, Almack K, Manning JC and Johnston B. Decision-making and future planning for children with life-limiting conditions: a qualitative systematic review and thematic synthesis. Child: Care, Health and Development. 2017; 43: 627-44.

3. Storch J and Kenny N. Shared Moral Work of Nurses and Physicians. Nursing ethics. 2007; 14: 478-91.

4. Baruch G. Moral tales: parents'stories of encounters with the health professions. Sociology of Health \& Illness. 1981; 3: 275-95.

5. Coffey M, Cohen R, Faulkner A, Hannigan B, Simpson A and Barlow S. Ordinary risks and accepted fictions: how contrasting and competing priorities work in risk assessment and mental health care planning. Health Expectations. 2017; 20: 471-83.

6. Coulter A. What's happening around the world? In: Edwards A and Elwyn G, (eds.). Shared Decision-making in Health Care: Achieving Evidence-based Patient Choice

Oxford: OUP 2009.

7. Park ES and Cho IY. Shared decision-making in the paediatric field: a literature review and concept analysis. Scandinavian Journal of Caring Sciences. 2018; 32: 478-89.

8. Boland L, Graham ID, Légaré F, et al. Barriers and facilitators of pediatric shared decisionmaking: a systematic review. Implementation Science. 2019; 14: 7.

9. Muirhead P. When parents and physicians disagree: What is the ethical pathway? Paediatr Child Health. 2004; 9: 85-6.

10. Carnevale FA, Teachman G and Bogossian A. A Relational Ethics Framework for Advancing Practice with Children with Complex Health Care Needs and Their Parents. Comprehensive Child and Adolescent Nursing. 2017; 40: 268-84.

11. Joseph-Williams N, Edwards A and Elwyn G. Power imbalance prevents shared decision making. BMJ (online). 2014; 348: g3178.

12. Opel DJ. A 4-Step Framework for Shared Decision-making in Pediatrics. Pediatrics. 2018; 142: S149-S56.

13. Children Act. UK: The Stationary Office, 1989.

14. Committee on Bioethics AAoP. Informed consent, parental permission, and assent in pediatric practice. Committee on Bioethics, American Academy of Pediatrics. Pediatrics. 1995; 95: 314-7.

15. Savulescu J. Rational non-interventional paternalism: why doctors ought to make judgments of what is best for their patients. Journal of Medical Ethics. 1995; 21: 327.

16. O'Keefe DJ. Persuasion: Theory and Research. London, UK: SAGE Publications, 2015.

17. Fisher KA, Tan ASL, Matlock DD, Saver B, Mazor KM and Pieterse AH. Keeping the patient in the center: Common challenges in the practice of shared decision making. Patient Education and Counseling. 2018; 101: 2195-201.

18. Swindell J, McGuire AL and Halpern SD. Beneficent persuasion: techniques and ethical guidelines to improve patients' decisions. The Annals of Family Medicine. 2010; 8: 260-4.

19. Stake RE. Multiple Case Study Analysis. New York: Guilford Press, 2006.

20. BERGER PL and LUCKMANN T. The Social Construction of Reality: A Treatise in the Sociology of Knowledge. London: The Penguin Press, 1966.

21. RUBIN HJ and RUBIN IS. Qualitative Interviewing: The Art of Hearing Data. London, UK: Sage Publications Ltd., 2005.

22. Caelli K, Ray L and Mill J. 'Clear as Mud': Toward Greater Clarity in Generic Qualitative Research. International Journal of Qualitative Methods. 2003; 2: 1-13.

23. SMITH J, BEKKER $\mathrm{H}$ and CHEATER F. Theoretical versus pragmatic design in qualitative research. Nurse Researcher. 2011; 18: 39-51. 
24. ACT and RCPCH. A guide to the Development of Children's Palliative Care Services. Bristol: Association for Children with Life-Threatening or Terminal Conditions and their Families (ACT) and Royal College of Paediatrics and Child Health (RCPCH). 1997.

25. Miles MB and Huberman MA. Qualitative Data Analysis: An Expanded Sourcebook. London, UK: SAGE Publications Ltd., 1994.

26. Carnevale FA, Macdonald ME, Bluebond-Langner $M$ and McKeever P. Using participant observation in pediatric health care settings: ethical challenges and solutions. Journal of Child Health Care. 2008; 12: 18-32.

27. Stake RE and SAGE. The Art of Case Study Research. SAGE Publications, 1995.

28. Clandinin DJ and Connelly FM. Narrative Inquiry: Experience and Story in Qualitative Research. San Fanscisco: Jossey-Bass Publishers, 2000.

29. Sandelowski M. Telling stories: narrative approaches in qualitative research. Journal of Nursing Scholarship. 1991; 23: 161-6.

30. Creswell JW. Qualitative Inquiry and Research Design: Choosing Among Five Approaches. London, UK: SAGE Publications, 2013.

31. Modi N, Vohra J, Preston J, et al. Guidance on clinical research involving infants, children and young people: an update for researchers and research ethics committees. Archives of disease in childhood. 2014; 99: 887-91.

32. Bateman LB, White ML, Tofil NM, Clair JM and Needham BL. A Qualitative Examination of Physician Gender and Parental Status in Pediatric End-of-Life Communication. Health communication. 2017; 32: 903-9.

33. Richards CA, Starks H, O'Connor MR, Bourget E, Hays RM and Doorenbos AZ. Physicians Perceptions of Shared Decision-Making in Neonatal and Pediatric Critical Care. The American Journal of Hospice and Palliative Care. 2018; 35: 669-76.

34. Wilkinson DJ and Truog RD. The luck of the draw: physician-related variability in end-of-life decision-making in intensive care. Intensive care medicine. 2013; 39: 1128-32.

35. Marteau TM. Framing of information: its influence upon decisions of doctors and patients. The British Journal of Social Psychology. 1989; 28 ( Pt 1): 89-94.

36. Haward MF, John LK, Lorenz JM and Fischhoff B. Effects of Description of Options on Parental Perinatal Decision-Making. Pediatrics. 2012; 129: 891-902.

37. Haward MF, Murphy RO and Lorenz JM. Message framing and perinatal decisions. Pediatrics. 2008; 122: 109-18.

38. GILLAM L. The zone of parental discretion: An ethical tool for dealing with disagreement between parents and doctors about medical treatment for a child. Clinical Ethics. 2016; 11: 1-8.

39. Barilan YM and Weintraub M. Persuasion as Respect for Persons: An Alternative View of Autonomy and of the Limits of Discourse. Journal of Medicine and Philosophy. 2001; 26: 13-34.

40. Maclean A. Autonomy, Consent and Persuasion. European Journal of Health Law. 2006: 321-

38.

41. Smith DH and Pettegrew LS. Mutual persuasion as a model for doctor-patient communication. Theoretical medicine. 1986; 7: 127-46.

42. Karnieli-Miller $O$ and Eisikovits Z. Physician as partner or salesman? Shared decision-making in real-time encounters. Social Science \& Medicine. 2009; 69: 1-8.

43. Lipstein EA, Dodds CM and Britto MT. Real life clinic visits do not match the ideals of shared decision making. J Pediatr. 2014; 165: 178-83.e1.

44. Power KJ. How are Ethical Problems Resolved in a Paediatric Intensive Care Unit? Faculty of Health and Life Sciences. De Montfort University, 2012.

45. Fiks AG, Hughes CC, Gafen A, Guevara JP and Barg FK. Contrasting parents' and pediatricians' perspectives on shared decision-making in ADHD. Pediatrics. 2011; 127: e188-96.

46. Birchley G, Gooberman-Hill R, Deans Z, Fraser J and Huxtable R. 'Best interests' in paediatric intensive care: an empirical ethics study. Arch Dis Child. 2017; 102: 930-5. 
47. Sandman $L$ and Munthe $C$. Shared decision making, paternalism and patient choice. Health care analysis : HCA : journal of health philosophy and policy. 2010; 18: 60-84.

48. Kaldjian LC. Communicating moral reasoning in medicine as an expression of respect for patients and integrity among professionals. Communication \& medicine. 2013; 10: 177-83. 


\section{Declarations}

\section{Authorship}

All named authors have made a substantial contribution to the design of the study and analysis of the data, drafted, or revised the manuscript and approved the submitted version.

\section{Funding}

The author(s) received no financial support for the research, authorship, and/or publication of this article.

\section{Declaration of conflicts of interest}

Dr Joseph Manning is currently funded through NIHR (National Institute for Health Research) HEE (Health Education England) ICA (Integrated Clinical Academic) Clinical Lectureship; the views expressed are those of the authors and not necessarily those of the NHS, the NIHR or the Department of Health and Social Care, UK. All other authors declare no conflict of interest.

\section{Data management and sharing}

This is a qualitative study and therefore the data generated is not suitable for sharing beyond that contained within the report. Further information can be obtained from the corresponding author.

\section{Acknowledgements}

Our sincere thanks to the families and professionals who took the time to contribute invaluable data to this study. 